\title{
Transições e reconfigurações do self de jovens indígenas na experiência universitária
}

\author{
Sueli Barros da Ressurreição \\ Universidade do Estado da Bahia - Salvador - BA - Brasil \\ Sonia Maria da Rocha Sampaio \\ Universidade Federal da Bahia - Salvador - BA - Brasil
}

\begin{abstract}
Resumo
Este artigo tem como propósito explicitar o papel da experiência universitária na reconfiguração do Self a partir das dimensões analisadas no desenvolvimento psicossocial, apontando contribuições da Psicologia Cultural. Extraído de uma pesquisa de abordagem qualitativa, apresenta um recorte empírico de uma entrevista episódica realizada com um estudante indígena universitário. Os resultados do estudo apontam que a experiência universitária é significada como espaço-tempo propício para transições, no qual as tensões entre os conhecimentos locais e científicos, os reconhecimentos entre os pares e o espaço dialógico intercultural são os aspectos mais destacados pelos estudantes, que os transformam em recursos simbólicos, promotores da reconfiguração do Self no contexto acadêmico. As conclusões confirmam que as dimensões do Self em contextos educativos são formadas e reativadas durante fases críticas da vida, momentos de mudanças, como o ingresso dos jovens na universidade, e de perspectiva temporal e de reposicionamentos identitários e socioculturais, que parecem típicos das transições juvenis.
\end{abstract}

Palavras-chave: Estudantes Universitários; desenvolvimento do adulto; Psicologia Escolar.

\section{Transitions and reconfigurations of indigenous self in university experience}

\begin{abstract}
This article aims to explain the role of university experience in the reconfiguration of the Self from the dimensions analyzed in psychosocial development, pointing to contributions of Cultural Psychology. Extracted from a qualitative approach, it presents an empirical cut of an episodic interview with an indigenous university student. The results of the study point out that university experience has a meaning as space-time conducive to transitions, in which the tensions between local and scientific knowledge, peer acknowledgments and intercultural dialog space are the highlights of the students, who transform into symbolic resources, promoters of the reconfiguration of the Self in the academic context. The conclusions confirm that the dimensions of the Self in educational contexts are formed and reactivated during critical phases of life, moments of change, such as the entry of young people into the university, and of identity and sociocultural repositioning, which seem typical of youth transitions.
\end{abstract}

Keywords: College Students; adult development; School Psychology.

\section{Transiciones y reconfiguraciones del self de jóvenes indígenas en la experiencia universitaria}

\begin{abstract}
Resumen
En este artículo se tiene el propósito explicitar el papel de la experiencia universitaria en la reconfiguración del Self a partir de las dimensiones analizadas en el desarrollo psicosocial, apuntando contribuciones de la Psicología Cultural. Extraído de una investigación de abordaje cualitativo, presenta un recorte empírico de una entrevista episódica realizada con un estudiante indígena universitario. Los resultados del estudio apuntan que la experiencia universitaria es significada como espacio-tiempo propicio para transiciones, en el cual las tensiones entre los conocimientos locales y científicos, los reconocimientos entre los pares y el espacio dialógico intercultural son los aspectos más destacados por los estudiantes, que los transforman en recursos simbólicos, promotores de la reconfiguración del Self en el contexto académico. Las conclusiones confirman que las dimensiones del Self en contextos educativos son formadas y reactivadas durante fases críticas de la vida, momentos de cambio, como el ingreso de los jóvenes en la universidad, y de perspectiva temporal e de reposicionamientos identitarios y socioculturales, que parecen típicos de las transiciones juveniles.
\end{abstract}

Palabras clave: Estudiantes Universitarios; desarrollo del adult; Psicología Escolar. 


\section{Introdução}

Os estudos sobre os percursos dos estudantes na universidade mostram que suas trajetórias são permeadas por experiências que podem ser sentidas como rupturas: modelo da educação básica para a educação superior, relação com o saber, ideologias, conceitos, crenças e hábitos. Pelo que afirmam, a vida universitária parece ser mais do que um simples cenário onde transitam os estudantes, constituindo uma arena de mudanças para sua trajetória de vida e marcando seu desenvolvimento psicossocial (Coulon, 2008; Santos \& Sampaio, 2012; Ressurreição, 2015).

Ao entrar na universidade, os jovens vivenciam tensões impactantes na organização do seu percurso de vida, rupturas afetivas e culturais, como reflexos das relações que estabelecem no contexto universitário, que os levam a construir novas referências identitárias, habilidades e significados, processo caracterizado como transições (Zittoun, 2004). Na vida universitária, as transições são ensejadas por experiências desafiadoras, prazerosas, mas também estressantes, que levam os estudantes a construírem estratégias de enfrentamento. Para muitos jovens oriundos de setores populares ou com histórico de preconceito étnico-racial, a experiência universitária possibilita a emergência de novos posicionamentos identitários devido à presença de outros significativos, aqui entendidos como recursos simbólicos que orientam a construção de novos conhecimentos, novas referências espaço-temporais, conflitos e confrontos.

No que se refere aos indígenas brasileiros, a conquista de direitos sociais passou por longos períodos de luta e resistências devido ao histórico de extermínio, exclusão social e apagamento de suas identidades. A população indígena foi reconhecida legalmente como titular de direitos na Constituição de 1988 e, a partir desta, foi assegurado o direito a uma educação diferenciada voltada para a proteção dos costumes, línguas, crenças, tradições e organizações sociais. Essa conquista abriu caminhos para uma nova frente de reivindicações: a oficialização de escolas correspondentes aos seus direitos e demandas que garantam educação multilíngue, intercultural, comunitária e voltada para a autodeterminação dos povos. E, através do fortalecimento da gestão dos territórios e organizações, emergiu mais um movimento de luta pela cidadania: o acesso e a permanência na educação superior como meio de apropriação dos conhecimentos científicos e técnicos, fortalecimento das gestões territoriais e participação efetiva nas formulações de políticas públicas nas aldeias indígenas (Lima, 2012).

Há, porém, um número relativamente pequeno de estudos que tematizam a etnicidade e questões psicossociais envolvidas no acesso e na permanência de estudantes indígenas neste nível de formação. Vitales e Grubits (2009) realizaram pesquisa do estado da arte sobre a temática indígena na área da Psicologia em quatro tipos de bancos de dados: o banco de teses do Portal Capes, a Biblioteca Digital de Teses e Dissertações (BDTD), a Biblioteca Virtual em Saúde - Psicologia (BVS-Psi) e a consulta aos acervos eletrônicos de bibliotecas de 30 Instituições de Educação Superior brasilei- ras. Notaram que os temas apresentam maior incidência em questões relativas à identidade/diferença, seguidos de mitos e mitologia, religiosidade, suicídio, dependência de drogas e outras ligadas à saúde em diferentes contextos. Quanto aos participantes da pesquisa, os autores registraram apenas uma pesquisa sobre universitárias indígenas.

Portanto, nota-se a necessidade de ampliar os estudos sobre as transições desses jovens que iniciam seus estudos superiores, através de contribuições da Psicologia do Desenvolvimento e da Educação. É nesse ponto que se insere o papel da Psicologia na educação superior, tendo como foco os processos de aprendizagem e de desenvolvimento psicossocial, comprometida com a formação de cidadãos críticos e transformadores. Historicamente, é uma área de atuação ainda pouco explorada pelos psicólogos e docentes e, quando ocorre há uma persistente inclinação para a ênfase clínica, numa perspectiva individualizada e fracionada no que tange ao contexto institucional e socioeducacional, restrita ao atendimento individual e aplicação de testes psicológicos. Por outro lado, nos últimos anos verificam-se propostas de atuação numa perspectiva preventiva e institucional no apoio aos discentes: acolhimento, formação acadêmica, relações interpessoais, estratégias de aprendizagem e desenvolvimento de competências. (Marinho-Araújo, 2011; Sampaio, 2011).

O propósito deste artigo é apresentar reflexões sobre a relevância das experiências universitárias na reconfiguração do Self, por meio da análise de um estudo de caso envolvendo um estudante indígena, apontando algumas contribuições da Psicologia Cultural aplicada no contexto da educação superior. Essas reflexões foram extraídas de uma pesquisa acadêmica, cuja temática apresenta um evidente recorte da dimensão étnico-racial. Entretanto, dada a delimitação do objetivo proposto no presente texto, os aspectos relativos à etnicidade não serão aqui aprofundados, conforme foram explorados e analisados em outros artigos relacionados à mesma pesquisa.

Através da análise de um estudo de caso, discutimos as principais categorias analíticas que norteiam o objeto de estudo da pesquisa para compreender como ocorrem as transformações no desenvolvimento psicossocial de estudantes indígenas no contexto da universidade: rupturas-transições, recursos simbólicos e a emergência do Self. As reflexões teóricas apresentadas, sobre os processos de transição do jovem, são suportadas pelo argumento de que as transições ocorrem em todo o curso do desenvolvimento humano, não apenas na juventude, e esta, por sua vez, não se reduz à sua condição de transitoriedade, mas como momento específico de experiências situadas no tempo e espaço histórico em que vive o sujeito (Pais, 1990; Zittoun, 2007).

As reflexões aqui apresentadas estão voltadas para o entendimento da singularidade dos sujeitos num contexto institucional que contribui para seu desenvolvimento, mas que também é transformado por eles. Assim, pode colaborar para práticas emancipatórias outorgadas pelos psicólogos ao participar da elaboração e da execução de políticas educacionais na perspectiva crítica (Meira \& Antunes, 2003; Patto, 1984). 


\section{Trajetórias de jovens universitários: rupturas/ transições e recursos simbólicos na educação superior}

A Psicologia Cultural de orientação semiótica é uma abordagem que considera a cultura como central no desenvolvimento humano e tem como categoria de análise os processos de significações (Valsiner, 2012). Assim, o diálogo interdisciplinar com a Antropologia é essencial para compreendermos o conceito de cultura. A cultura é aqui entendida conforme a perspectiva de Geertz (2001) e de Barth (2011), como um sistema simbólico que compõe os processos psíquicos, dinamicamente reconstruído nas fronteiras entre os grupos, assumindo o papel central de mediador com o qual os atores compartilham, interpretam e reconfiguram sentidos e significados.

Geertz (2001), ao apontar as contribuições da Psicologia Cultural nos trabalhos de Jerome Bruner, afirma que o projeto desse psicólogo, muito mais do que acrescentar "cultura" ("sentido" ou "narrativa") ao estudo da mente, foi o de chamar atenção para o enfrentamento da realidade como um campo de diferenças. O Self (o si-mesmo) constitui-se de significados internalizados e reinterpretados pelo sujeito na sua matriz sociocultural, emergentes dos diálogos ocorridos nas suas experiências (Bruner, 2001). Nessa perspectiva, o Self pode ser definido como signo campo que organiza as identidades, coordena as experiências passadas com as relações sociais do presente e fornece orientações para o futuro, mediado pela cultura.

Na perspectiva sociocultural da educação postulada por Bruner (2001), o sujeito da aprendizagem é protagonista do seu processo de escolarização, ao mesmo tempo em que é constituído pela cultura organizacional onde se insere. As experiências educacionais são parte das trajetórias de vida e desempenham papel crucial no desenvolvimento do sujeito. A educação é a busca constante de adequação de uma cultura às necessidades dos sujeitos e ao modo como estes significam os saberes socializados para ajustar-se às necessidades do seu grupo social. Nessa perspectiva, é possível observar que a universidade fornece um legado rico de elementos culturais que facilitam as transições no desenvolvimento dos jovens nos processos de aprendizagem. A vida acadêmica põe em evidência as diferenças culturais de cognição, principalmente naqueles jovens submetidos a um histórico de escolaridade menos favorável à apropriação rápida das ferramentas necessárias na educação superior.

Ao desenvolver suas pesquisas, Zittoun (2012b) propõe dois modelos para analisar a dinâmica psicossocial das transições na área da educação. O primeiro é considerar rupturas sentidas como descontinuidades que levam a transições na aprendizagem, nos processos identitários e na construção de significados. E o segundo modelo proposto é analisar as transições como reconfigurações do prisma semiótico, que articula Self, outros significativos, o objeto e o sentido do objeto, numa situação social específica. Seguimos aqui essa proposta teórico-metodológica para análise do desenvolvimento psicossocial de jovens acadêmicos.
Ancorada na perspectiva da Psicologia Cultural e transitando entre os saberes das Ciências Sociais, Zittoun (2005, 2007) define rupturas/transições como unidade de análise para compreender o desenvolvimento psicológico, uma vez que permite o estudo dos processos de mudança no nível da aquisição de habilidades, posicionamentos identitários e na construção de significados. Esse par representa o ajuste entre a pessoa e seu ambiente sociocultural na dinâmica do desenvolvimento, uma vez que as pessoas não se movimentam em trajetórias lineares e, sim, em percursos de rupturas ou pontos de bifurcação, seguidos por transições, em todo o curso da vida.

As rupturas são tensões marcantes na vida das pessoas, advindas de vários episódios ocorridos no seu percurso (imigração, transformações corporais, escolaridade, mobilidade social, catástrofes e outros). Elas podem ser descritas como pontos de bifurcação, atuando como catalisadoras para as mudanças intransitivas, ou seja, momentos em que as continuidades no desenvolvimento são interrompidas, reorientadas e desafiadas, e a pessoa vai em busca de novos arranjos em seu Self (Zittoun, 2009). Porém, as rupturas só são sentidas como relevantes quando acompanhadas de incertezas, que podem ser paralisantes ou estimulantes, reelaboradas por meio de processos de transição. Assim, são seguidas por transições, processos que reduzem as incertezas, pois ensejam possibilidades de reposicionamentos ou relocações nos campos socioafetivo e simbólico da experiência da pessoa, reconfigurando o Self e gerando novidade (Valsiner, 2012).

As transições são ocasiões para o desenvolvimento, sendo designadas como processos de ajustamento para novas circunstâncias. Estão presentes nos eventos sociopsicológicos e sugerem algo que está em trânsito de um estado para outro, podendo levar a resultados imprevisíveis no que concerne às novas perspectivas de futuro e reconfigurações nas dimensões socioafetivas e simbólicas da experiência. Desse modo, o requisito para uma transição no desenvolvimento é a relocação social e cultural, que vem acompanhada pelo desafio de abandonar ou reformular identidades, rotinas e representações de realidade.

A pessoa é suscetível a diferentes transições nas diversas esferas da experiência, em momentos e ritmos diferentes. Assim, a experiência de rupturas-transições envolve mudanças em três dimensões intimamente ligadas e interdependentes nas diversas esferas da experiência: processos de aprendizagem (relocação cultural), processos identitários (posicionamentos e reconhecimentos) e construção de significados.

Os processos de aprendizagem consistem em relocações nos campos sociais e simbólicos, que exigem a aquisição de novos conhecimentos e habilidades, redefinindo, dessa forma, os modos de pensar e agir. Segundo a autora, a aprendizagem ocorre na relação que o sujeito estabelece com seu contexto, que precisa fazer algum sentido para ele, o que implica um processo de construção de significados. Essa visão da aprendizagem ancora-se na perspectiva teórica de Lev S. Vygotsky e Jerome Bruner (Zittoun, 2015). 
Na perspectiva de Vygotsky (1988), a aprendizagem é socialmente construída através da evolução dos significados compartilhados socialmente e internalizados pelo sujeito que assimila e confere novos sentidos aos saberes socializados. Desse modo, o aprender desperta os processos de desenvolvimento ao contribuir para a aquisição e organização de novas estruturas psicológicas. Por sua vez, as novas estruturas criam uma zona (ou área) potencial para novas aprendizagens, proporcionando maior nível de desenvolvimento através da mediação semiótica presente nas relações entre sujeito-outro-objeto. Processos de aprendizagem e processos de desenvolvimento não são idênticos, mas formam uma unidade onde um pode ser convertido no outro. Os processos de desenvolvimento são movimentados pela aprendizagem que se dá no nível intersubjetivo e, como tal, devem ser analisados de maneira prospectiva, como referência ao que está para acontecer na trajetória do sujeito. Ao se apropriar dos elementos culturais, a pessoa constrói novos signos para se relacionar com a realidade, que atuam como reguladores nos processos de pensamento, planejamento, coordenação e administração de suas emoções, crenças e condutas.

Nessa mesma direção, Bruner (2001) afirma que as pessoas constroem realidades e ordenam as experiências em episódios significativos por meio das narrativas, umas das formas de geração de conhecimento. Nesse sentido, a via para o entendimento da pessoa está na forma como a experiência e a ação são organizadas na sua mente e que, por sua vez, só podem ser compreendidas a partir do conjunto de sistemas culturais nas quais estão envolvidas. Esclarece que a cultura tem o papel de fornecer os significados para essa organização através das palavras, das artes, dos costumes e tradições, que são os signos socialmente compartilhados responsáveis por guiar ações, pensamentos e sentimentos.

Aqui se insere outra dimensão das transições - a construção de significados -, processo pelo qual a pessoa internaliza as mudanças e interpreta situações, eventos, objetos ou discursos da cultura coletiva, à luz de seus conhecimentos e expectativas de sua cultura pessoal, que passam a orientar as trajetórias de seu desenvolvimento (Zittoun, 2005). No enfrentamento das mudanças, a pessoa constrói novos significados nas suas narrativas, expressões emocionais e recursos simbólicos. A elaboração desses significados implica a reconfiguração da própria subjetividade, em parte consciente, corporal e emocional e que configura identidades.

Ao fazer essa relação com a construção de identidades, a autora aponta um nível existencial de construção de significados envolvidos na aprendizagem que emerge das rupturas ou incertezas ocorridas na trajetória de uma pessoa. Conforme a perspectiva semiótica, na experiência de ruptura a pessoa questiona ou reconstrói seu ponto de vista sobre seu passado e suas perspectivas de futuro. Por ser carregada de emoção, essa experiência tanto pode contribuir quanto impedir os processos reais de aprendizagem de objetos, dos outros e do mundo (Zittoun, 2012a). Desse modo, as rupturas-transições provocam uma reconfiguração no sistema de orientação, que consiste na base através da qual as pessoas conferem sentido a suas experiências e as transformam em afetos, valores e sentidos traduzidos nas narrativas.

Os processos identitários também são vivências que compõem as transições. Eles abrangem os reposicionamentos, ou seja, as transformações das identidades ocorridas no contexto familiar, no educacional profissional, na representação de si mesmo e como a pessoa é reconhecida pelos outros significativos. São maneiras de criar novas metas, orientações, possibilidades, pressões sobre ações e perdas, confrontos, por meio de práticas discursivas, que implicam mudanças de posicionamentos (Zittoun, 2005).

Na perspectiva da Psicologia Cultural, o Self assume múltiplas faces em diferentes inscrições de sua história, organiza diferentes identidades e vozes mobilizadas no âmbito interpessoal. Assim, a todo o momento, ocorrem rearranjos identitários para dar conta da tensão entre identidade para si e para o Outro. Os processos identitários são definidos pelas relações dialógicas entre a identidade pessoal ou interna e a identidade social ou pertencimentos nas diversas esferas da experiência, articulando diferenças e semelhanças dos diversos atores envolvidos.

Almejando compreender como ocorre, nos indivíduos, essa construção, Zittoun (2007) analisa a relação de interdependência entre cultura pessoal e coletiva, apoiada nos estudos de Jaan Valsiner. A cultura pessoal compõe o que denomina de face pessoal ou interna da construção identitária, abrangendo a internalização e a reapropriação dos significados socialmente compartilhados de forma singular, no contexto das experiências passadas, corporais e emocionais do sujeito. A cultura coletiva reúne os elementos culturais que consistem em complexas constelações simbólicas, como objetos ou ritos dentro da família, tradições religiosas ou nacionais, as artes, os quais são compatilhados e organizados em unidades semióticas disponíveis em uma dada sociedade. Segundo Zittoun (2012a), ela integra a face da identidade social, ou seja, as experiências de reconhecimento e pertencimento por parte de certos grupos ou redes socias, isto é, a identidade para o Outro nas diversas esferas da experiência. Nesse ponto de vista, os posicionamentos identitários emergem da síntese dinâmica entre essas culturas, dois lados de uma mesma moeda.

A autora ressalta que, nas sociedades ocidentais, certos aspectos nos jovens são mais evidenciados e reconhecidos do que outros, como a valorização de certas competências, experiências corporais ou emocionais. O entendimento das transições juvenis, nessa perspectiva teórica, centra-se nos recursos simbólicos como mediadores do modo de pensar, sentir e agir do ciclo aprendizagem, processos identitários e a construção de significados. As pesquisas de Zittoun (2009) esclarecem que nem todas as dimensões do ciclo são mobilizadas ao mesmo tempo, mas a mudança em uma delas afeta as demais. Essas dimensões podem se desenvolver em uma das esferas da experiência, a exemplo da escolarização, mas o ciclo pode se desconectar em outras. Porém, progressivamente, as transformações se estendem para outras esferas, a exemplo da família ou do trabalho. Essa dinâmica no ciclo das dimensões é mediada e fortale- 
cida por recursos simbólicos, permitindo que a pessoa tome distância de sua própria experiência, extraia conhecimentos e ferramentas semióticas, modifique sua compreensão da realidade e posicionamentos identitários construindo, assim, novos significados.

De acordo com Zittoun (2007), os recursos simbólicos desempenham papel central nos processos de transição. Primeiramente, porque apoiam e orientam as experiências afetivas e imaginárias; em segundo lugar, porque fornecem meios semióticos para organizar e transformar as experiências pessoais. E, finalmente, ao permitirem ao sujeito tomar distância de sua própria realidade e recorrer a seus próprios recursos pessoais, favorecem a mediação das experiências passadas no enfrentamento das tensões ou rupturas vivenciadas no presente. Os jovens, ante a diversidade nas transições de papéis e a confrontação com novos valores e condutas, reconfiguram seu sistema de orientação, adquirindo o que a autora denomina de responsabilidade simbólica. Esse tipo de responsabilidade corresponde à conquista de autonomia pelo jovem para gerar sua própria temporalidade, conferir sentido a si e aos outros e orientar suas escolhas e perspectivas futuras.

A responsabilidade é denominada simbólica por Zittoun (2007) porque, nesta etapa da vida, o jovem é desafiado a assumir relações, críticas, escolhas, reconstruções de regras e condutas na interação com seus interlocutores significativos em diferentes esferas da experiência: pais, comunidade, igreja, escola, grupo de amigos, trabalho e outros. A responsabilidade simbólica consiste na maneira como o jovem organiza a perspectiva de tempo e o seu próprio sistema de orientação, através de internalizações e externalizações, processos relacionados com a cultura pessoal e coletiva. $\mathrm{Na}$ cultura pessoal, o sujeito internaliza e se apropria dos significados compartilhados na cultura coletiva, mostrando sua autonomia e singularidade. Para isso, o jovem, de forma subjetiva e original, realiza uma bricolagem com os elementos culturais disponíveis na cultura coletiva, transformando-os em recursos simbólicos para lidar com a realidade circundante e orientar suas trajetórias. A responsabilidade simbólica pode ser definida, então, como a forma simbólica encontrada pelos jovens para construir seu sistema de orientação.

No estudo empírico que será descrito a seguir, observamos nas narrativas do estudante que o espaço universitário parece ser um campo fértil para aquisição da responsabilidade simbólica, ao possibilitar a reflexão de valores, modelos de conduta, normas, repertórios simbólicos, experiências emocionais, conhecimento e práticas, os quais integram as relações dialógicas. Desse modo, as experiências acadêmicas, através dos seus elementos culturais, podem ser catalisadoras de novos sistemas de orientação desses jovens em outras esferas do seu ciclo de vida.

\section{Procedimentos metodológicos: estudo de caso}

O estudo de caso discutido neste artigo consiste num recorte extraído de uma pesquisa de abordagem qualitativa de cunho etnográfico, concluída no ano de 2015, norteada pelo objetivo de compreender os significados atribuídos por estudantes indígenas às histórias de rupturas e transições no seu desenvolvimento psicossocial, que ocorrem a partir do acesso e ao longo de seus estudos. Aqui interessa aprofundar em um dos seus objetivos específicos: apresentar reflexões sobre a relevância das experiências universitárias na reconfiguração do Self de jovens acadêmicos, apontando algumas contribuições da Psicologia Cultural aplicada no contexto da educação superior.

Consideramos o enfoque etnográfico alinhado ao propósito deste estudo, pois a etnografia quer obter uma descrição densa e mais completa possível das ações, narrativas, crenças, percepções e interpretações das pessoas, relativas às suas experiências no mundo social. Pressupõe uma descrição cultural e busca entender, em profundidade, os significados atribuídos pelos sujeitos a si próprios e às suas experiências, permitindo análise descritiva e interpretativa dos significados simbólicos, conotativos e denotativos que informam as práticas usuais na vida cotidiana (Uzzel \& Barnett, 2010).

Ancoradas nesta perspectiva, recorremos ao método das narrativas para produção dos dados, através da realização de entrevista episódica (Flick, 2008), na qual buscamos, nos episódios biográficos, os posicionamentos identitários e recursos afetivos, cognitivos e simbólicos usados pelos jovens para auxiliar a organização do seu desenvolvimento. No guia de entrevista, buscamos identificar, por meio das questões, episódios da experiência pessoal que apresentassem as principais rupturas e transições após o ingresso na universidade. As entrevistas foram realizadas em salas de aulas da própria instituição universitária e, orientadas pelos aspectos éticos da pesquisa com seres humanos, foram gravadas com o consentimento do estudante, após esclarecimentos acerca dos objetivos da pesquisa, dos procedimentos da entrevista e da assinatura do Termo de Consentimento Livre e Esclarecido.

Os participantes foram oito estudantes indígenas com idade entre18 e 29 anos, de ambos os sexos, que já haviam concluído o primeiro ano de curso em áreas de conhecimento diversas. Todos eles haviam ingressado através do sistema de cotas étnico-raciais, e faziam sua formação superior numa universidade pública na capital do estado da Bahia. A análise dos casos enfatizou a identificação de núcleos temáticos centrados nas ambivalências e signos emergentes das narrativas sobre trajetórias e posicionamentos identitários relacionados com as transições no contexto universitário.

Neste artigo, discutimos apenas um dos casos estudados, devido à singularidade de cada participante, considerando os limites de extensão determinados para o presente texto e a relevância dos aspectos das narrativas do estudante escolhido relacionados aos recursos simbólicos e reconfigurações identitárias nas transições, categorias que permeiam o propósito principal deste artigo. 


\section{Resultados e discussão: "Umã Gama-Iniciar uma nova história."}

$\mathrm{Na}$ ocasião da pesquisa, o estudante entrevistado, com o pseudônimo de Umã Gama, era do $3^{\circ}$ semestre do curso de Medicina, tinha 23 anos, solteiro, sem filhos, filho de pai e mãe indígenas pertencentes à Etnia Atikum-Umã da Aldeia Quixabá, localizada no estado de Pernambuco e ingressante em universidade pública pelo sistema de cotas. O bloco temático da entrevista episódica destinou-se a fazer o entrevistado refletir sobre o sentido geral do tema e identificar aspectos e eventos percebidos como rupturas, seguidas por transições, a partir de sua trajetória de acesso à educação superior e da definição subjetiva sobre sua experiência universitária.

Ao narrar sobre sua trajetória de acesso à educação superior, o estudante apresentou ter pleno conhecimento acerca das carências de bens e serviços básicos existentes na sua comunidade, das precárias estruturas de habitação à falta de profissionais da área de saúde para atender à população, e enfatiza: "Eu senti na pele como é essa carência...". Logo que nasceu, seus pais se separaram, foi educado por sua mãe, com sua irmã e seu irmão, hoje com 33 e 35 anos, respectivamente. A irmã realizou o seu sonho de ser professora, fez graduação e pós-graduação na área de geografia, em Pernambuco, o irmão não seguiu carreira acadêmica na universidade. Ao relembrar sua história de escolaridade, enfatiza que a mãe, apesar de não ter estudado, sempre o incentivou a prosseguir nos seus estudos.

Sobre a sua aspiração pela educação superior, o estudante apresenta um primeiro aspecto ambivalente em referência ao seu grupo étnico, pois não queria seguir o padrão da maioria das pessoas que permaneciam lá em situação precária de emprego: "Eu quero fazer algo mais, eu quero um curso superior, não quero isso aqui para mim". Umã Gama também afirma que a saída de outras pessoas da comunidade para fazer medicina serviu de exemplo para o desafio de tentar fazer também o mesmo curso. Ao mesmo tempo, esse desejo o moveu para a construção de um compromisso de fazer o curso de Medicina e voltar para a comunidade: "Eu vou fazer um curso superior, de medicina, e vou vir para cá, para minha cidade..., eu vou fazer o possível para ajudar essas pessoas que sempre necessitam e que são a minha família, são conhecidas, pessoas próximas e que realmente necessitam". Consideramos esse momento da história do estudante como ponto de ruptura, ele transcendeu o padrão da maioria de sua comunidade, tomando a decisão de cursar educação superior, mas, ao mesmo tempo, carregou o desejo de voltar para a comunidade e ajudar aqueles que necessitam.

Zittoun (2012c), ao analisar os "dispositivos transitórios" ${ }^{1}$ dos jovens adultos europeus, explica que a transição para o mundo do trabalho é considerada "normativa", pois adquirem novos saberes e habilidades para acompanhar e dar retorno ao seu grupo a fim de serem formalmente re-

1 Tradução nossa. conhecidos como ocupantes de uma nova posição social. Esses dispositivos consistem no fortalecimento de certas aprendizagens escolares e no desenvolvimento de competências sociais. Aqui no Brasil e, principalmente na Região Nordeste, esses dispositivos não são empregados de forma homogênea e nem adequada para todas as classes sociais. A rede pública de ensino, onde se concentra a população de baixa renda, está ainda muito distante de oferecer a seus alunos uma educação que englobe saberes e práticas compatíveis com aqueles oferecidos na rede privada. Além disso, o tempo destinado para aprendizagem é notadamente inferior àquele investido nas escolas particulares, embora ambas sigam o mesmo calendário acadêmico orientado pelo Ministério da Educação (MEC). É possível observar esse fato na narrativa de Umã Gama sobre sua escolaridade, norteada pela dificuldade que a escola pública tem para trabalhar o conhecimento:

Eu sofri isso bastante e ainda mais quando fui me preparar para o vestibular. A escola pública fornece o básico, o básico realmente, e, quando você se defronta com o vestibular e quando chega na universidade, você tem este mundo maior do que você tinha estudado. Então, você tem que estudar muito mais, virar muito mais noite, para tentar recuperar este tempo perdido, que deixou a desejar em todo este tempo de percurso de escola, de alfabetização, de escola pública em si. A universidade oferece essa gama de conhecimento, muito aprofundado, muito profundo e você tem que fazer o possivel para recuperar tudo o que você deixou para trás.

Conforme a Psicologia Cultural, no processo de construção de significados, os signos assumem duas funções: a de regular, quando reconstrói ou atende às demandas de um determinado processo no presente; e a de promover, ao fornecer orientação para abordar o futuro (Valsiner, 2012). O posicionamento "recuperar o tempo perdido" no conhecimento, que revela não ter obtido, apresentou-se como signo regulador ao integrar o Self desse estudante durante os dois anos em que fez pré-vestibular, atuando como guia para superar as lacunas de sua escolaridade e orientando suas perspectivas para o futuro. Várias vezes ele duvidou se daria conta para aprender tanta coisa em tão pouco tempo e, por isso, "virava a noite" para acompanhar os conteúdos. Este foi um momento em que o jovem revela ter sofrido bastante, ficava tenso e desorientado. Todavia, solicitou a ajuda do professor de cursinho, revelando-lhe suas dificuldades no ensino básico, e isso contribuiu para expandir seu campo cognitivo, resultando na sua aprovação no vestibular.

Desde os primeiros anos de sua escolarização, Umã Gama é guiado pelo signo "estudante esforçado e disciplinado". Na universidade, esse signo adquire maior valência, pois o conhecimento torna-se, para ele, o recurso simbólico central para enfrentar as tensões advindas do novo modelo de aprender. Ao relacionar a vida acadêmica ao seu cotidiano, revela que os processos de transição para esse novo modelo contribuíram para a aquisição de competências e de maior controle do seu tempo de estudo, significando uma 
ruptura como o modelo do ensino-aprendizagem da educação básica. Essa ruptura agiu como um dos mediadores catalíticos no seu processo de transição, pois atuou como apoio contextual para mudanças na dimensão da aprendizagem, da habilidade nas relações interpessoais e na organização de sua orientação espaço-temporal:

Antes, eu tinha um problema nesta questão de horário quando eu cheguei na universidade, de você estar presente nos horários, nas aulas que foram marcadas. Não só isso, mas na questão de relacionamento com as pessoas, de você saber contornar uma situação. Eu ando de ônibus todos os dias e ônibus é um problema enorme, você está lidando com muitas pessoas ali. Então, surge um problema, você tem que saber contornar a situação da melhor forma possível, eu acho isso interessante e a universidade está aprimorando.

Os novos conhecimentos adquiridos podem ser também considerados como catalisadores, pois favoreceram as condições necessárias, atuando como recursos simbólicos para seu amadurecimento e aquisição de competências. O desenvolvimento de novas habilidades cognitivas afetou outras dimensões, como os posicionamentos identitários e a construção de significados. Essas mudanças foram transferidas para outras esferas da experiência, na relação com sua própria família e na relação cotidiana com as pessoas de modo geral, daí a importância que atribui ao aprendizado adquirido na universidade para sua própria vida.

Destacamos aqui a função reguladora do Self, orientada pela unidade cognição-afeto-ação de onde emerge a construção de significados: "Esta vida de universidade está sendo legal, é cansativa, realmente é muito cansativa, mas é boa. Para mim, tem um significado muito importante de aquisição de experiências e do conhecimento em si". Essa narrativa ilustra como a subjetividade desse estudante emerge a partir do que aprendeu na experiência universitária, na síntese da dinâmica intrapessoal e interpessoal.

Na universidade, Umã Gama expressa sua subjetividade na forma como lida com os conhecimentos e nas relações interpessoais. Nos episódios narrativos, é possível identificar os desafios enfrentados que o impelem a tomar decisões, elaborar conceitos e críticas e reconstruir as regras e condutas com pessoas, conhecimentos e outros recursos culturais significativos para sua experiência. Uma vez internalizados e ressignificados, esses recursos Ihe conferem responsabilidade simbólica na universidade, por expressar reorganização no seu sistema de orientação nos níveis semântico, existencial e pragmático (Zittoun, 2007; 2009). Umã Gama explica o impacto do papel da universidade no seu cotidiano:

A universidade hoje desempenha um papel de não só de trazer maior quantidade de conhecimentos, mas de amadurecimento. Este período que estou passando na universidade, estou convivendo não só com meus colegas, mas com os professores. São fatores que estão agregando e me trazem amadurecimento...
No nível semântico, ele constrói novos significados acerca de suas experiências passadas com base nas interações atuais como acadêmico. Deseja dominar o conhecimento técnico-científico e tornar-se um profissional competente, mas, ao mesmo tempo, almeja que sua atuação seja permeada pela ética, tornando-se cada vez mais o que denomina "ser pensante":

A junção do conhecimento científico, o conhecimento ético e até mesmo [pausa], tudo isso agrega para você se tornar um ser pensante, cada vez mais pensante. Um ser cada vez mais preocupado com a sua vivência interpessoal, preocupado com o que você pode fazer, não só como profissional, mas enquanto pessoa, como ser adulto na sociedade e que isso possa não só beneficiar você, mas as pessoas que estão também ao seu redor. Então, tudo isso faz com que você seja aquela pessoa que saiba e que ponha este saber em prática. Eu acho isso importante.

Nesse posicionamento, é possível identificar o aspecto existencial na construção dos significados sobre o saber acadêmico, guiado pelos signos "estudante disciplinado e esforçado" e o "pensador do futuro", os quais agregam as identidades pessoal e coletiva, ou fluxos semióticos que tecem sua subjetividade (Zittoun, 2012b). Este é um ponto de ruptura de importante impacto na história de Umã Gama, pois Ihe confere novas habilidades cognitivas e a construção de novos significados também no nível pragmático. Esse nível pode ser observado na sua narrativa referente aos etnométodos envolvidos no seu processo de afiliação institucional e acadêmica, aqui denominado de pertencimento acadêmico. Ele viveu um período de estranhamento (Coulon, 2008), sentiu a universidade como mundo novo, algo que marcou a sua relação com os outros e com sua forma "acanhada" de ser e, no início, não sabia se permaneceria no curso:

Então, ao chegar, no primeiro dia de aula, realmente eu fiquei me sentindo assim fora, será que esse é o lugar que vou passar bem os seis anos... Mas foi só início, essa coisa de iniciar uma nova história, deixa você um pouco receoso... Eu lembro que eu sentei na aula de produção textual, eu comecei a pensar como se eu não estivesse na aula. Alguns colegas já se conheciam e eu ficava com receio de chegar para conversar e pensava: "O que eu vou conversar com eles? Que assunto eu vou tratar com eles?”. Eu fiquei na aula pensando nisso, fiquei como se eu não fizesse parte da sala de aula. Fiquei bem assim acanhado, mas depois foi tranquilo.

Esse estranhamento parece ter sido vivido, inicialmente, como uma descontinuidade no seu desenvolvimento, antes era muito acanhado, mas diante das tensões foi impelido a mudar de posição e interagir com os colegas. Hoje, sente-se integrado à universidade, como se ela fosse uma "segunda família", explicou. Na fronteira entre ser universitário para si e ser universitário para o outro, há uma tensão entre a cultura pessoal e a cultura coletiva, de onde emer- 
gem novos posicionamentos identitários como mecanismos de orientação para o futuro. O estudante é guiado pelo signo "iniciar uma nova história" que representa a emergência do seu Self na experiência universitária e cria nova estabilidade dinâmica na sua cultura pessoal.

Ao mesmo tempo, o signo "conhecimento novo" torna-se também um recurso simbólico mediador de suas transições de pertencimento étnico e, assim, das mudanças nos seus posicionamentos identitários durante sua formação na universidade. O pertencimento étnico é expresso na forma como ressignifica o conhecimento adquirido na universidade, que, segundo ele, Ihe enseja a oportunidade de "viver uma nova história" para si e para seu grupo étnico: “... esse conhecimento novo que estou adquirindo vai ser muito importante para quando eu voltar para minha aldeia. Porque o que eu quero é voltar para lá. Vai ser um conhecimento que vou usar e compartilhar dentro de minha aldeia". O estudante declara um compromisso explícito e espontâneo para com sua comunidade de origem, cujo vínculo está diretamente ligado a sua história familiar. Umã Gama fala do papel que desempenha hoje, como universitário, na sua comunidade:

Eu visito a minha comunidade duas vezes ao ano. Agora estamos tentando ver, na verdade, nós não, eu estou tentando ver um projeto de alguns estudantes de Carnaubeira que fazem Medicina em Brasília, eles estão fazendo palestras na comunidade, que é um papel que eu já poderia estar fazendo. Então, agora, estou pensando em me inserir nesse grupo. Até o momento, eu não tinha como, porque estava pegando a base na universidade, mas agora já dá para participar deste grupo. São palestras realizadas nas escolas, é algo novo que está inserido agora, e estou participando, acredito que agora em julho. Esse é um papel que posso fazer agora como estudante, buscando compartilhar com minha comunidade.

Conforme Barth (2011), o contato com outras etnias provoca alterações nas expressões culturais dos grupos e, assim, reconfigura suas identidades. A narrativa de Umã Gama ilustra a forma como os símbolos de sua cultura étnica e os conhecimentos adquiridos na universidade são transformados por ele e como são integrados no seu Self, ou, como denominado por ele, na sua "nova história". Ao se reportar aos conteúdos aprendidos na universidade, ele consegue com facilidade relacioná-los com a realidade vivida por sua gente.

É notório que as mudanças nos processos de aprendizagem e de aquisição de novas habilidades, provocadas pelo acesso e permanência na universidade, mobilizaram os processos identitários e a construção de novos significados no ciclo de transição desse estudante. $O$ signo promotor, generalizado, que guiou essas mudanças, foi o conhecimento vivido a cada dia e negociado e compartilhado com os outros significativos e ressignificados pelo estudante, preservando a unidade do seu Self com relevante impacto no seu desenvolvimento psicossocial:
Antes da universidade, eu tinha várias dúvidas: "Eu faço isso ou não"; e na universidade eu estou me tornando uma pessoa mais objetiva em relação ao que quero fazer e também à escolha do que quero fazer, do melhor caminho a seguir, de forma mais objetiva também. E em todas as relações interpessoais, a UNEB me proporcionou ser uma pessoa de compartilhar atitudes, compartilhar mais experiências. Porque eu era uma pessoa mais fechada.

As mudanças catalisadas, ou transições, foram percebidas também na esfera da experiência familiar. Ele destaca a base psicológica proporcionada pela mãe e pela irmã, que the conferiram confiança e responsabilidade. Apesar da distância geográfica, o vínculo com elas tornou-se mais forte: "Esta relação de carinho vai durar pelo resto da vida". A entrada na universidade permitiu também uma reaproximação com seu pai e outros irmãos paternos, passando a frequentar a sua casa e dele receber apoio financeiro. Esse apoio familiar é condição para sua permanência, pois a carga horária do curso não permite que desenvolva atividades remuneradas. Ele é beneficiário da bolsa-auxílio integral na universidade, mas, após meses em atraso, até o momento da entrevista só haviam sido pagos duas prestações. Sem a ajuda dos pais, não teria condições de arcar com o necessário para continuar estudando.

O signo "iniciar uma nova história" passa a regular a experiência de Umã Gama na universidade, reconstruindo dialogicamente o seu Self na sua relação com os conhecimentos e sentimentos vivenciados. A sua narrativa sugere que os recursos simbólicos que compõem as primeiras experiências de sua escolaridade, permanecem presentes após a sua entrada na universidade, a exemplo dos membros de sua família e as tradições indígenas, regulados pelo signo "estudante esforçado e disciplinado". Mediado pelos conhecimentos, signo promotor, o estudante cria perspectivas futuras, tensionado pelo signo "o pensador do futuro". Esse signo se organiza através de uma nova orientação no seu sistema de valores como a ética profissional, a responsabilidade com o outro, a alteridade, o compromisso comunitário, incorporados e ressignificados na sua subjetividade.

\section{Considerações finais}

Analisamos aqui alguns dos marcadores de rupturas-transições vivenciadas pelo jovem no contexto da educação superior que contribuem para a reconfiguração do Self. Os resultados mostram que a experiência universitária é significada como espaço-tempo propício para transições, no qual as rupturas atuam como agentes catalisadores, promovendo a emergência de processos de autorregulação que orientam as trajetórias dos estudantes. A vivência dessas rupturas consistiu em tensões intersubjetivas que levaram o estudante a ressignificar seus discursos, crenças, sentidos, atitudes e perspectivas de vida, reconfigurando seu sistema de orientação espaço-temporal. A experiência universitária contribuiu para rupturas/transições através 
das interações estabelecidas com o saber acadêmico, regras institucionais, professores, colegas e funcionários que se apresentam como coparticipantes do seu processo de desenvolvimento.

Neste sentido, a universidade constitui-se como mediadora para a emergência de novas funções psicológicas ao proporcionar aos estudantes constante reinterpretação e reconfigurações de conhecimentos, ideologias, tradições, comportamentos e significados. Nesse espaço, é possível observar as contradições: as desigualdades sociais, o diálogo intercultural, formas de organização social, crenças, diferentes comportamentos, pertencimentos e práticas culturais. A vivência dessas contradições envolve complexas relações constituintes do sujeito

A discussão deste tema desperta a necessidade de novos estudos que possam contribuir para problematizar os aportes teóricos da Psicologia na área da Educação, com foco nos processos de aprendizagem e desenvolvimento humano na perspectiva histórica, crítica e reflexiva. No que concerne ao psicólogo que atua no ensino superior torna-se necessário buscar novos eixos de atuação. Diante de um novo e heterogêneo público discente, decorrente das reformas de acesso às universidades públicas, torna-se premente sua colaboração nas propostas que operacionalizem estruturas de suporte material e humano para garantir qualidade na execução de tarefas acadêmicas, permanência e o sucesso acadêmico dos discentes, e para o planejamento de atividades de ensino, pesquisa e extensão.

Conforme propõem Matos e Sampaio (2013), essa intervenção pressupõe a elaboração de uma pedagogia da afiliação que torne a orientação acadêmica uma política que construa suporte institucional estruturado, uma vez que a responsabilidade de se tornar estudante não apenas deve ser outorgada ao esforço e à persistência pessoal do jovem, nem a seus professores, mas a toda a comunidade acadêmica. No presente estudo foi possível constatar que os conhecimentos científicos atuam como signos promotores nas transições dos jovens na universidade ao entender que a reconfiguração do Self possibilita diferentes direções em suas trajetórias e temporalidades envolvidas na tensão entre suas experiências e os elementos culturais disponíveis na vida universitária. E, assim, a atuação do psicólogo pode ser centrada na relação que os estudantes estabelecem com o saber, com base nos processos de afiliação, ou, em outras palavras, nos modos peculiares de pertencer ao contexto universitário, e nas ações desenvolvidas para se tornar membro efetivo do grupo de acadêmicos.

\section{Referências}

Barth, F. (2011). Os grupos étnicos e suas fronteiras. Em P. Poutignat, P.\& J. Streiff-Fernart (Orgs.), Teorias da etnicidade (2a.ed., pp.185227).São Paulo: Ed. Unesp.

Bruner, J. (2001). A cultura da educação. Porto Alegre: Artes Médicas.
Coulon, A. (2008) A condição de estudante: a entrada na vida universitária. Salvador: Edufba.

Flick, U. (2008). Entrevista episódica. Em M.W. Bauer \& G. Gaskell (Orgs.), Pesquisa qualitativa com texto, imagem e som: um manual prático (pp.114-136). Petrópolis, RJ: Vozes.

Geertz, C. (2001). Nova luz sobre a antropologia. Rio de Janeiro: Zahar.

Lima, A. C. S. (2012). A educação superior de indígenas no Brasil contemporâneo: reflexões sobre ações do projeto trilhas do conhecimento. Revista História, 1 (2), 169-193.

Marinho-Araújo, C. M. \& Bisinoto, C. (2011). Psicologia escolar na educação superior. Em R. L. S. Guzzo \& C. M. Marinho-Araújo (Orgs.), Psicologia escolar: identificando e superando barreiras (pp.193-214). São Paulo: Alínea.

Matos, R. L. \& Sampaio, S.M.R. (2013). A Orientação acadêmica entre a disciplinaridade e a interdisciplinaridade. Em G. G. Santos \& S. M. R. Sampaio (Orgs.), Observatório da Vida Estudantil: universidade, responsabilidade social e juventude (pp. 121-141). Salvador: Edufba.

Meira, M.E.M. \& Antunes, M.A.M. (2003). Psicologia Escolar: teorias críticas. São Paulo: Casa do Psicólogo.

Pais, J.M.A. (1990). A construção sociológica a juventude: alguns atributos. Análise Social, (25), 105-106. Recuperado: 16 jul. 2011. Disponível: http://www.ics.ul.pt/rdonweb-docs/Jos\%C3\%A9\% 20Machado\%20Pais\%20- pdf .

Patto, M.H.S. (1984). Psicologia e ideologia: uma introdução crítica à psicologia escolar. São Paulo: T.A. Queiroz.

Ressurreição, S.B. (2015). Jovens indígenas universitários: experiências de transições e etnogênese acadêmica nas fronteiras interculturais do desenvolvimento. Tese de Doutorado em Psicologia, Universidade Federal da Bahia, Salvador.

Sampaio, S.M.R. (2011). Educação superior como espaço privilegiado para orientação acadêmica. Em R.S.L. Guzzo \& C.M. MarinhoAraújo (Orgs.), Psicologia escolar: identificando e superando barreiras (pp.215-228). São Paulo: Alínea.

Santos, G.G. \& Sampaio, S.M.S. (Org.). (2012). Observatório da vida estudantil: estudos sobre a vida e culturas. Salvador: Edufba.

Uzzel, D. \& Barnett, J. (2010). Pesquisa etnográfica e pesquisa-ação. Em G. B. Breakwell (Org.), Métodos de pesquisa em psicologia(pp. 302-320). Porto Alegre: Artmed.

Valsiner, J. (2007). Culture in Minds and Societies. New Delhi: Sage.

Valsiner, J. (2012). Fundamentos de uma psicologia cultural: mundos da mente, mundos da vida. (A.C.S. Bastos, Trad., Rev. técnica). Porto Alegre: Artmed. 
Vitales, M.P. \& Grubits, S. (2009). Psicologia e povos indígenas: um estudo preliminar do "estado da arte". Revista Psicologia e Saúde, 1(1), 15-30.

Vygotsky, L.S. (1988). A formação social da mente. (Cipolla Neto J. \& cols., Trad.). São Paulo: Martins Fontes.

Zittoun, T. (2005).Transitions: symbolic resources in development. Charlotte, NC: Information Age Publishing.

Zittoun, T. (2007). Symbolic resources and responsibility in transitions. Young, 15(2), 193-211

Zittoun, T. (2009). Dynamic of Life-Course Transitions: a methodolological reflection. Published in Dynamic Process
Methodology in the Social and Developmental Sciences, chapter $18,405-429$

Zittoun, T. (2012a). Life course: A sociocultural perspective. Em J. Valsiner, J. (Org.). The Oxford Handbook of Culture and Psychology (pp.513-535). New York: Oxford University Press.

Zittoun, T. (2012b). On the emergence of the subject. Psychological and Behavioral Science, 46(3), 256-273.

Zittoun, T. (2012c). Une psychologie des transitions: des ruptures aux ressources. Em P. Curchod, P. A. Doudin, \& L. Lafortune (Orgs.), Accompagner les transitions du préscolaire à l'université. (pp.261279). Québec: Presses de l'Université du Québec.

Recebido em: 10 de julho de 2016

Aprovado em: 13 de junho de 2017

\section{Sobre as autoras}

Sueli Barros da Ressurreição (suelibarros13@gmail.com)

Docente da Universidade do Estado da Bahia (UNEB), Salvador-Bahia/Brasil. Doutora em Psicologia pela Universidade Federal da Bahia (POSPSI/UFBA).

Sonia Maria da Rocha Sampaio (sonia.sampaio@terra.com.br) Docente do Programa de Pós-Graduação em Psicologia (POSPSI/UFBA). Doutora em Educação pela Faculdade de Educação/Universidade Federal da Bahia (FACED/UFBA).

O artigo resulta de um recorte da Tese de Doutorado na área de Psicologia do Desenvolvimento de autoria de Sueli Barros da Ressurreição sob orientação de Sonia Maria da Rocha Sampaio, defendida no programa de Pós-graduação em Psicologia/UFBA, ano de 2015, com o nome de Jovens indígenas universitários: experiências de transições e etnogênese acadêmica nas fronteiras interculturais do desenvolvimento. $\mathrm{O}$ projeto de tese foi inscrito, avaliado na Plataforma Brasil e aprovado pelo Conselho de Ética e Pesquisa (CEP) da Universidade do Estado da Bahia (UNEB), segundo Parecer $n^{\circ} 338.065 / 2013$, na ocasião com o título provisório de Estudantes universitários indígenas: histórias de rupturas e transições. 